\title{
Implementasi Teknologi Augmented Reality Untuk Memperkenalkan Makanan Tradisional
}

\author{
Sam'an Alghozy ${ }^{\star 1}$, Endah Sudarmilah ${ }^{2}$ \\ ${ }^{1,2}$ Program Studi Informatika, Universitas Muhammadiyah Surakarta \\ e-mail: Dian7896@gmail.com*
}

\begin{abstract}
Indonesia is a nation which has a lot of natural and cultural resources, one of the culture products is a traditional food. Traditional food is closely related to regions and tribes, therefore, each of those is having its own tastes. Traditional food does not include in Indonesia formal education institution's subject of culture. It is possible for traditional food to be forgotten, therefore, there should be preservation needed and intention to introduce traditional food to remain well known. Augmented Reality (AR) used as a media to introduce traditional foods, $A R$ was chosen because it could provide information with educative and entertaining. Users may interact with food as if the food is in front of them. Development of the system uses unity and vuforia as software which intended for smartphones with the Android operating system. This system serves 16 types of traditional Indonesian food which are viewed in 3 dimensions (3D) form. 3D objects which have realistic and educative information make the system accepted by users positively with the average value of the SUS (System Usability Scale) 78.
\end{abstract}

Keyword: Augmented Reality; Traditional food; Unity; Vuforia

Abstrak

Indonesia adalah negara yang kaya akan sumber daya alam dan budaya, salah satu produk dari budaya adalah makanan tradisional. makanan tradisional berhubungan erat dengan daerah atau suku, oleh karena itu selalu berbeda cita rasa disetiap daerah. Makanan tradisional tidak masuk muatan materi mata pelajaran kebudayaan di lembaga pendidikan formal. Tidak menutup kemungkinan makanan tradisional dilupakan, maka perlu ada upaya pelestarian dan pengenalan agar makanan tradisional tetap dikenal. Augmented Reality (AR) dipilih sebagai media untuk memperkenalkan makanan tradisional, AR dipilih karena mampu menyajikan informasi dengan edukatif dan menghibur. Pengguna bisa berinteraksi dengan objek makanan seakan makanan yang asli ada didepan mereka. Pembangunan sistem menggunakan software unity, dan vuforia yang diperuntukkan untuk smartphone dengan sistem operasi android. Sistem ini berisi 16 jenis makanan tradisional Indonesia yang ditampilkan dalam bentuk 3 dimensi (3D). Objek 3D yang realistis dan informasi yang edukatif membuat sistem diterima secara positif dengan nilai rata -rata SUS (System Usability Scale) 78

Kata kunci: Augmented reality; Makanan tradisional; Unity; Vuforia

\section{Pendahuluan}

Indonesia adalah negara dengan kekayaan sumber daya alam dan budaya yang melimpah, keberagaman budaya membuat selera dan ciri khas berbeda disetiap daerah. Salah satu produk dari budaya adalah makanan tradisional. Makanan tradisional dimasak dan diramu oleh masyarakat tertentu, sehingga cita rasa dan peruntukan makanan yang dibuat berbeda dengan makanan lain.

Makanan tradisional tidak di ajarkan secara langsung di lembaga pendidikan formal sebagai bagian dari mata pelajaran kebudayaan, informasi tentang makanan tradisional hanya disampaikan melalui komunikasi dan kebiasaan hidup masyarakat. Tidak menutup kemungkinan makanan tradisional akan tergerus dengan makanan luar negeri bahkan dilupakan. Makanan tradisional penting dipelajari atau dilestarikan karena berdampak pada identitas, representasi budaya, sdan memajukan sektor pariwisata[1].

Teknologi informasi berkembang pesat seiring kemajuan ilmu pengetahuan. Informasi yang disajikan semakin beragam tidak hanya teks, audio, maupun video, kini informasi dapat 
ditampilkan melalui objek 3 dimensi(3D) [2]. Objek 3D dikembangkan untuk memenuhi berbagai kebutuhan seperti berita, pendidikan, dan hiburan. Teknologi yang memungkinkan fungsi objek 3D sebagai informasi sekaligus hiburan adalah Augmented Reality (AR). AR dapat dikembangkan diberbagai perangkat mobile seperti perangkat android.

AR menghubungkan dunia nyata dan dunia virtual secara realtime yang memungkinkan kita untuk berinteraksi dengan objek virtual setiap saat, dengan ini penggunan mendapat gambaran terhadap objek nyata dengan bantuan visualisasi objek 3D [3]. AR dapat digunakan dengan marker based tracking atau tanpa marker (markerless), pada metode markerless pengguna dapat menggunakan marker selain gambar seperti face recocnition dan motion tracking [4].

Penelitian kali ini menggunakan marker based tracking methode. Metode ini menggunakan gambar unik 2 dimensi (2D) sebagai marker, objek 3D akan muncul di sekitar marker dan mengikuti marker [5]. AR dapat menggunakan single marker atau multi marker untuk memunculkan objek. Single marker menggunakan marker tunggal dan memunculkan objek tunggal, sedangkan multi marker memungkinkan kombinasi beberapa gambar dan untuk menampilkan banyak objek dalam waktu yang bersamaan [6] . Marker model single marker dipilih untuk penelitian ini dengan alasan lebih mudah, karena setiap objek makanan hanya membutuhkan satu marker yang sama. Teknologi AR di pilih sebagai media pembelajaran makanan tradisional karena mampu menampilkan informasi yang menarik, sekaligus berinteraksi langsung dengan objek 3D, sehingga terbentuk media pembelajaran yang interaktif dan edukatif [7].

\section{Metode Penelitian}

Perancangan sistem menggunakan metode SDLC (System Development Life Cycle) model Waterfall. Penulis memilih model Waterfall karena langkah pembuatan yang berurutan. Waterfall adalah model yang populer digunakan untuk mengerjakan proyek seperti proyek proyek pemerintahan [8].

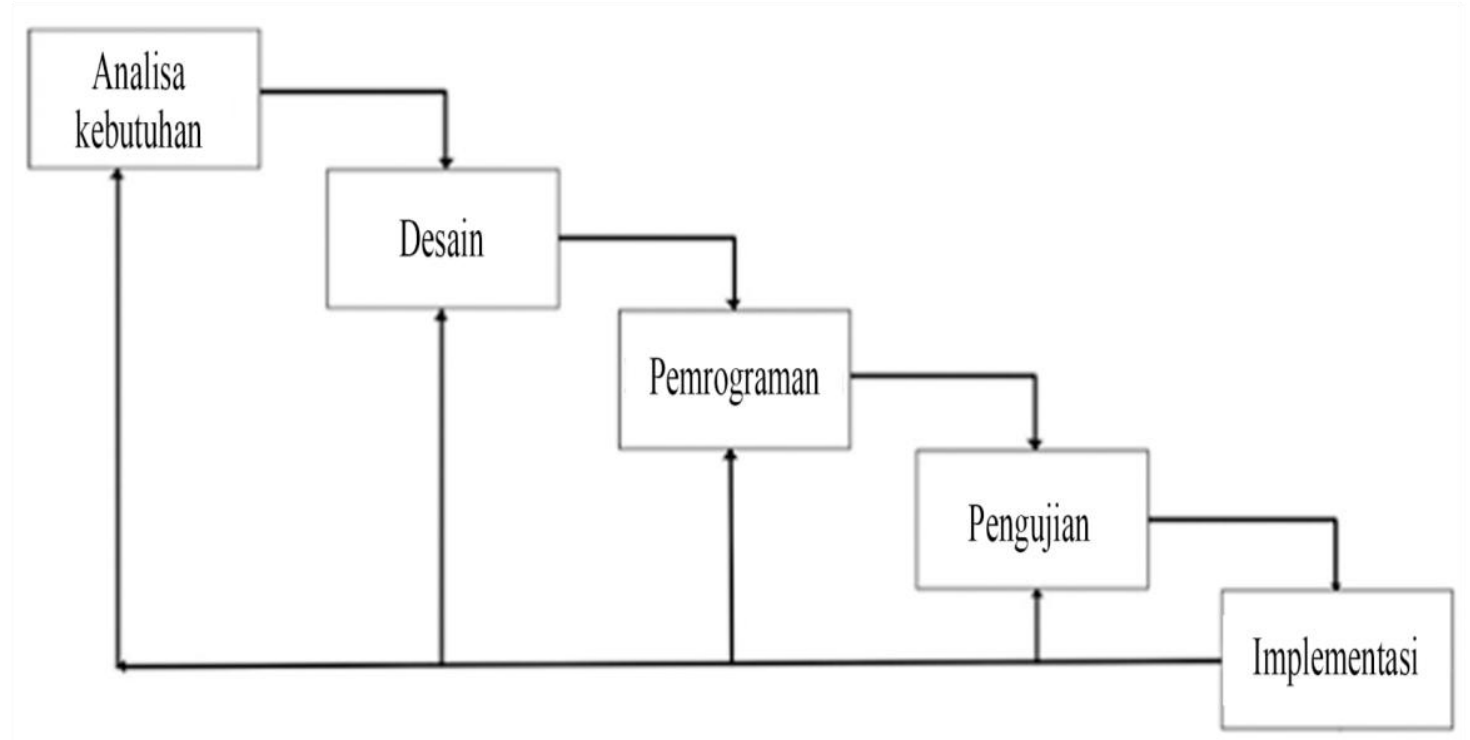

Gambar 1. Metode Waterfall SDLC

Proses perancangan sistem untuk memperkenalkan makanan tradisional memiliki beberapa tahapan yang berurutan, yaitu Analisa kebutuhan, Desain, pemrograman, Pengujian, implementasi. Apabila setelah proses implementasi sistem yang terbentuk belum sesuai dengan yang diharapkan, maka berlaku siklus rekursif.

\subsection{Analisis Kebutuhan}

Tahapan ini melakukan Analisa tentang apa yang dibutuhkan agar dapat menunjang penelitian berdasarkan data dan permasalahan yang di alami, sistem harus mampu memberikan 


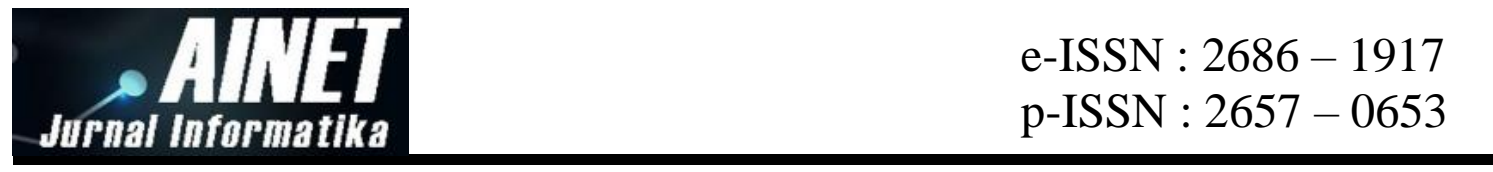

informasi, menampilkan objek 3D di setelah marker dipindai, dan visualisai objek 3D yang mendekati objek asli. Pembuatan sistem memerlukan alat yang dirincikan pada tabel 1 .

Tabel 1. Alat dan bahan pembuatan sistem

\begin{tabular}{cc}
\hline Software & Hardware \\
\hline Adobe photoshop CC 2017, Untuk & Notebook ASUS A555LB-XO048D \\
membuat marker dan grafis sistem & \\
$\begin{array}{c}\text { Android SDK untuk mengoprasikan AR } \\
\text { di perangkat mobile android }\end{array}$ & Smarthphone Samsung Galaxy Note 9 \\
Blender 2.8 untuk membuat objek 3D & \\
Unity 2019, sebagai editor aplikasi & \\
Visual studio 2017, untuk pengetikan \\
kode sistem \\
Vuforia, Untuk engine AR \\
\hline
\end{tabular}

\subsection{Desain}

Pengguna dapat melakukan beberapa hal dalam sistem. Ketika sistem dimulai maka sistem akan menampilkan peta Indonesia, dari scene peta Indonesia pengguna dapat memilih scene lanjutan daerah asal makanan yang dibagi menjadi beberapa pulau, kemudian pengguna dapat memilih salah satu makanan dalam daftar yang memicu sistem untuk menampilkan informasi beserta objek 3D makanan tradisional. Gambaran use case diagram terdapat pada Gambar 2.

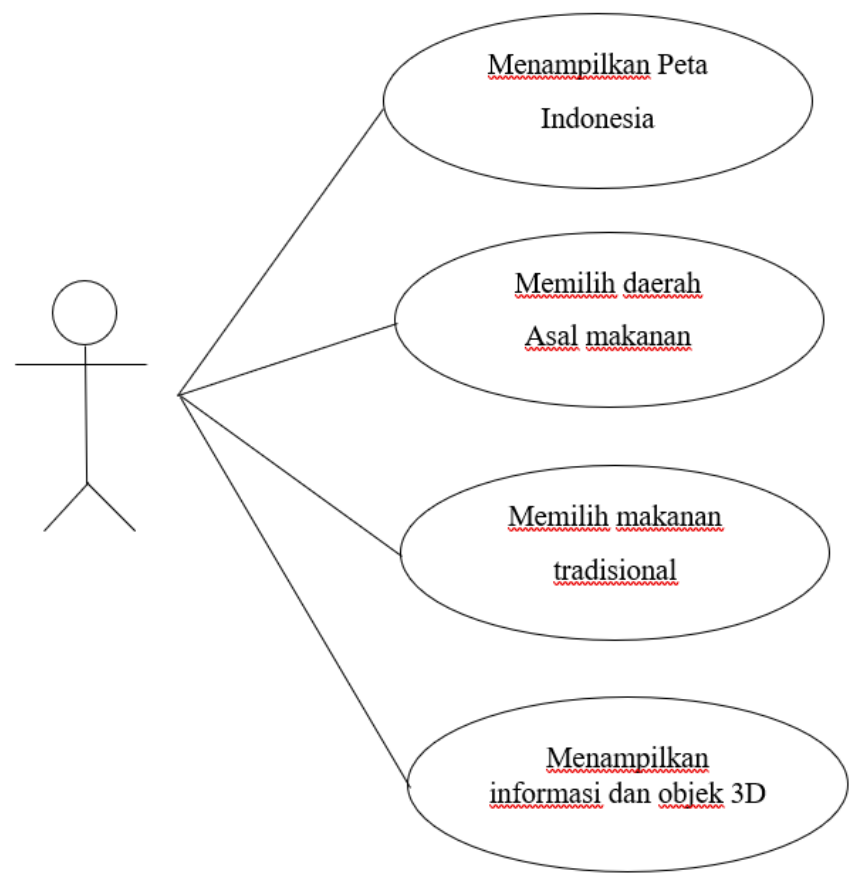

Gambar 2. Use Case Diagram

Diagram aktifitas menggambarkan bagaimana urutan sebuah sistem bekerja. Pengguna dapat memulai permainan dengan menekan tombol play, memilih asal daerah dan makanan, serta menampilkan objek 3D makanan tradisional. Gambaran activity diagram pada gambar 3. 


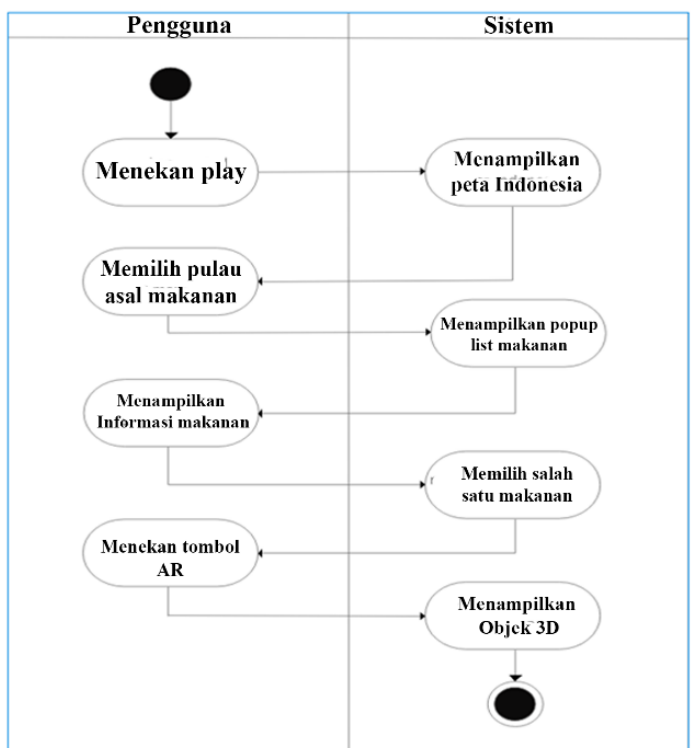

Gambar 3. Activity Diagram

\subsection{Pemrograman}

Sistem ini dibangun menggunakan software unity sebagai editor. Unity digunakan untuk pemrograman selain engine AR, seperti fungsi menampilkan objek, menyembunyikan objek, permainan suara, efek transisi dan berpindah scene. Unity tidak memiliki engine yang mampu menjalankan AR, agar AR dapat di implementasikan dalam sistem maka dibutuhkan aplikasi lain yang terintegrasi dengan unity yaitu vuforia. Sistem harus memiliki UI (User Interface) yang baik dan informatif, seluruh informasi dan asset grafis di buat menggunakan Adobe Photoshop CC 2017. Objek 3D sebagai informasi utama dibuat dengan Blender 2.8. Sistem memiliki 16 macam item makanan tradisional, oleh karena itu sistem ini memiliki 16 scene yang secara fungsi sama namun memiliki informasi yang berbeda.

\subsection{Pengujian}

Tahap lanjutan setelah sistem selesai dibuat adalah pengujian, pengujian sistem menggunakan metode pengujian black box dan pengujian usabilitas. Pengujian black box bertujuan untuk mengetahui apakah UI dan fungsi sistem yang dibuat sudah sesuai seperti yang diharapkan. Pengujian black box dilakukan mandiri oleh pembuat sistem berkebalikan dengan pengujian usabilitas. Pengujian usabilitas melibatkan pengguna. Pengguna akan menilai sistem yang di uji seperti seberapa mudah sistem dijalankan, kemudahan memahami informasi yang ditampilkan, seberapa jauh interaksi sistem dan pengguna, dan apakah sistem yang dibuat memenuhi kebutuhan pengguna.

\subsection{Implementasi}

Tahap terakhir pembangunan sistem dengan metode waterfall yaitu implementasi. Sistem pada tahap ini sudah memenuhi kriteria lolos pengujian, dan sistem siap digunakan. Pada tahap ini diterapkan evaluasi untuk menyesuaikan keinginan pengguna yang terus berkembang seiring waktu, dan perawatan apabila sistem mengalami gangguan atau kegagalan fungsi.

\section{Hasil dan diskusi}

Penelitian ini menghasilkan sistem dengan nama makanan tradisional dalam augmented reality. Sistem ini ditujukan untuk memperkenalkan makanan tradisional kepada masyarakat umum, sehingga semakin banyak orang yang mengetahui beragam jenis makanan tradisional. Operating System (OS) yang dipilih adalah android, OS ini dipilih karena lebih banyak digunakan dibandingkan OS lain, sehingga lebih banyak orang yang bisa memanfaatkan sistem ini. Pengguna dapat memilih 16 jenis makanan tradisional yang berbeda, makanan digolongkan berdasarkan pulau agar pengguna mengenali makanan dari tiap pulau. informasi makanan ditampilkan secara singkat dan mudah dipahami. Sistem ini dibagun dengan software unity dan vuforia dengan hasil berupa aplikasi android .apk. 


\begin{tabular}{ll} 
Jurnal informatika & e-ISSN : $2686-1917$ \\
sthe & p-ISSN : $2657-0653$ \\
\hline
\end{tabular}

\subsection{Halaman Awal}

Halaman awal terdiri dari tombol play, about, dan quit. Tombol play digunakan untuk memulai sistem, peta Indonesia akan ditampilkan setelah tombol ditekan. Tombol about berfungsi menampilkan informasi pembuat sistem, dan yang terakhir tombol quit untuk keluar dari aplikasi. Tampilan dari halaman awal digambarkan pada gambar 4 .

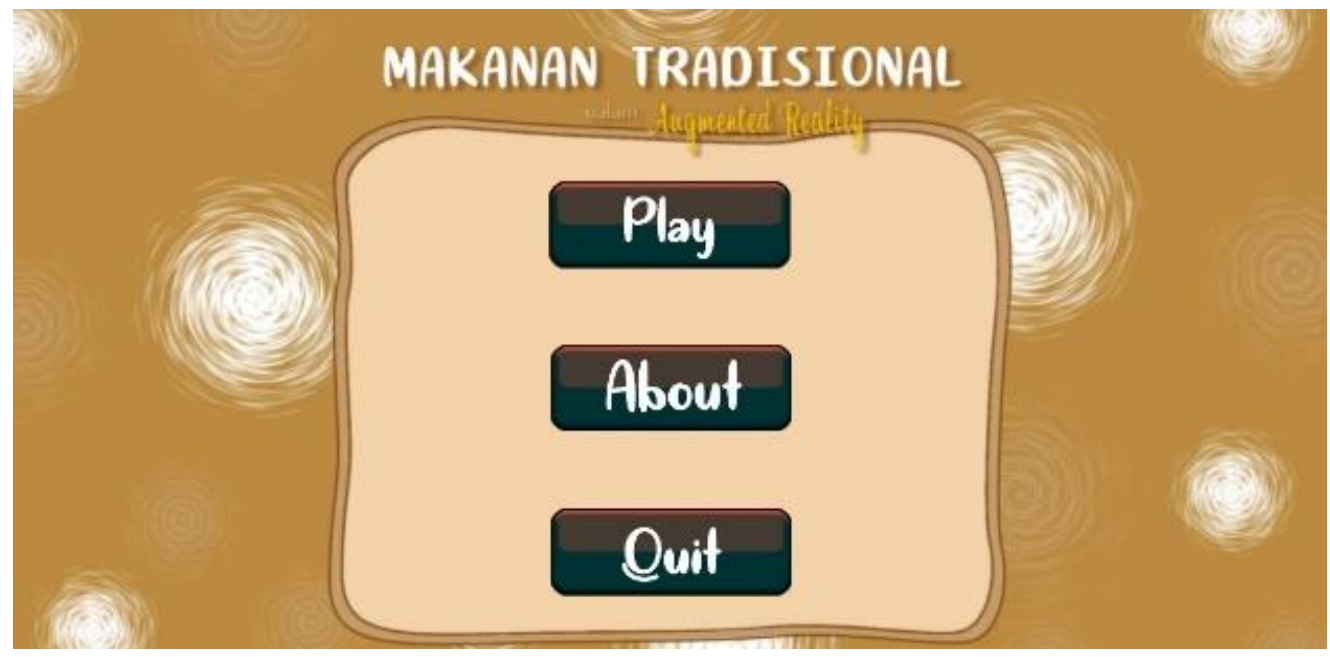

Gambar 4. Halaman Awal

\subsection{Halaman Peta Indonesia}

Halaman peta Indonesia menggambarkan penyebaran makanan tradisional, dibagi menjadi 4 bagian yaitu Sumatra, jawa, Kalimantan, dan Sulawesi. Alasan dibagi berdasarkan pulau agar lebih mudah memahami asal makanan secara berurutan, dimulai dari yang terbesar yaitu pulau, provinsi, kemudian ke kota. Apabila tombol pada pulau di klik, maka sistem akan menampilkan popup daftar makanan. Gambaran halaman peta Indonesia digambarkan pada Gambar 5.

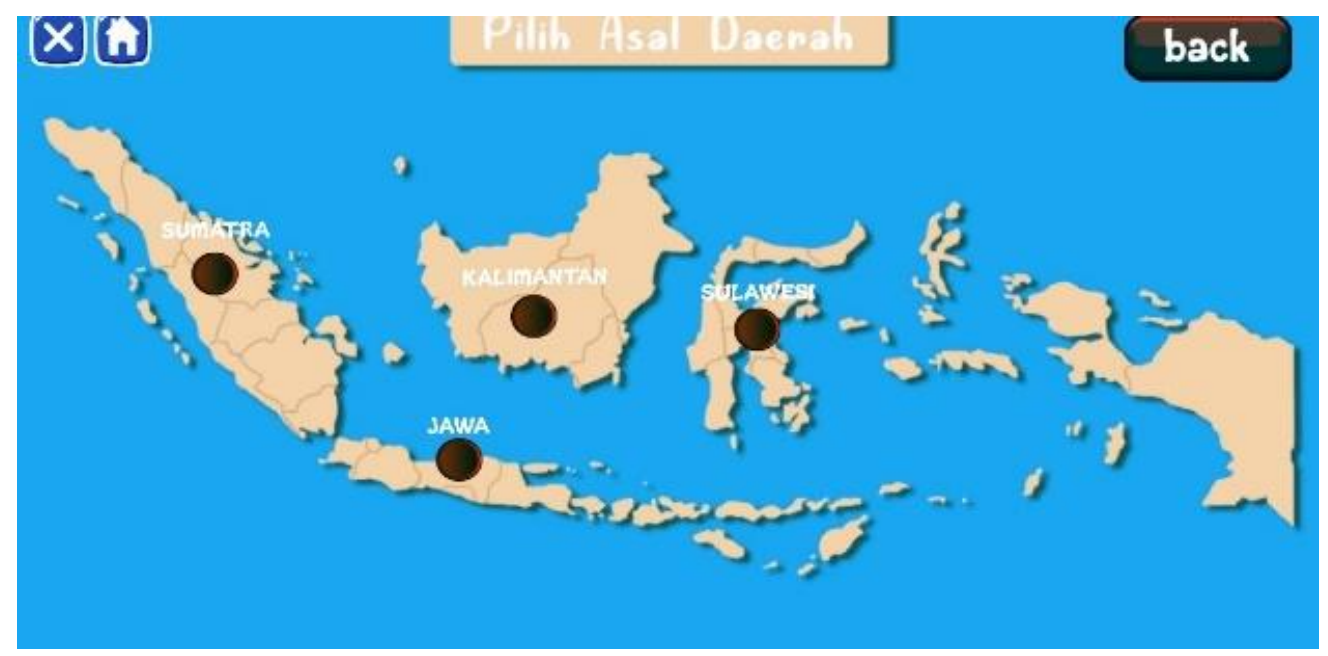

Gambar 5. Halaman Peta Indonesia

\subsection{Halaman Daftar Makanan}

Halaman daftar makanan berisi kumpulan makanan dari pulau yang sama, terdiri dari 4 popup yang berbeda berdasarkan pulau asal makanan tradisional. Pada sistem ini setiap pulau memiliki jumlah makanan yang berbeda, sumatra 3 macam, jawa 9 macam, Kalimantan 2 macam, dan Sulawesi 2 macam. Pengguna bebas memilih makanan apa yang ingin ditampilkan oleh sistem. Kumpulan halaman daftar makanan dari setiap pulau dapat dilihat pada Gambar 6. 


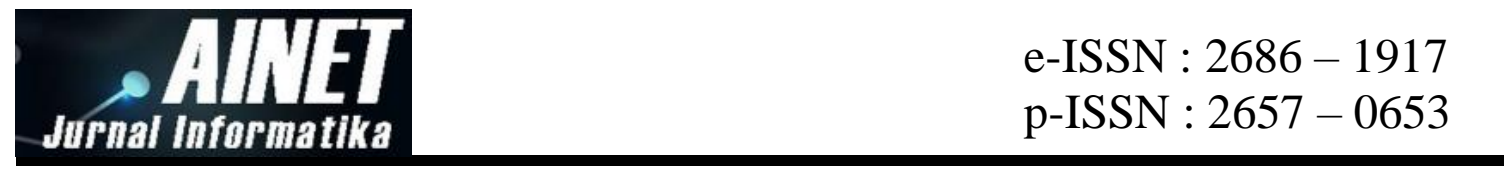

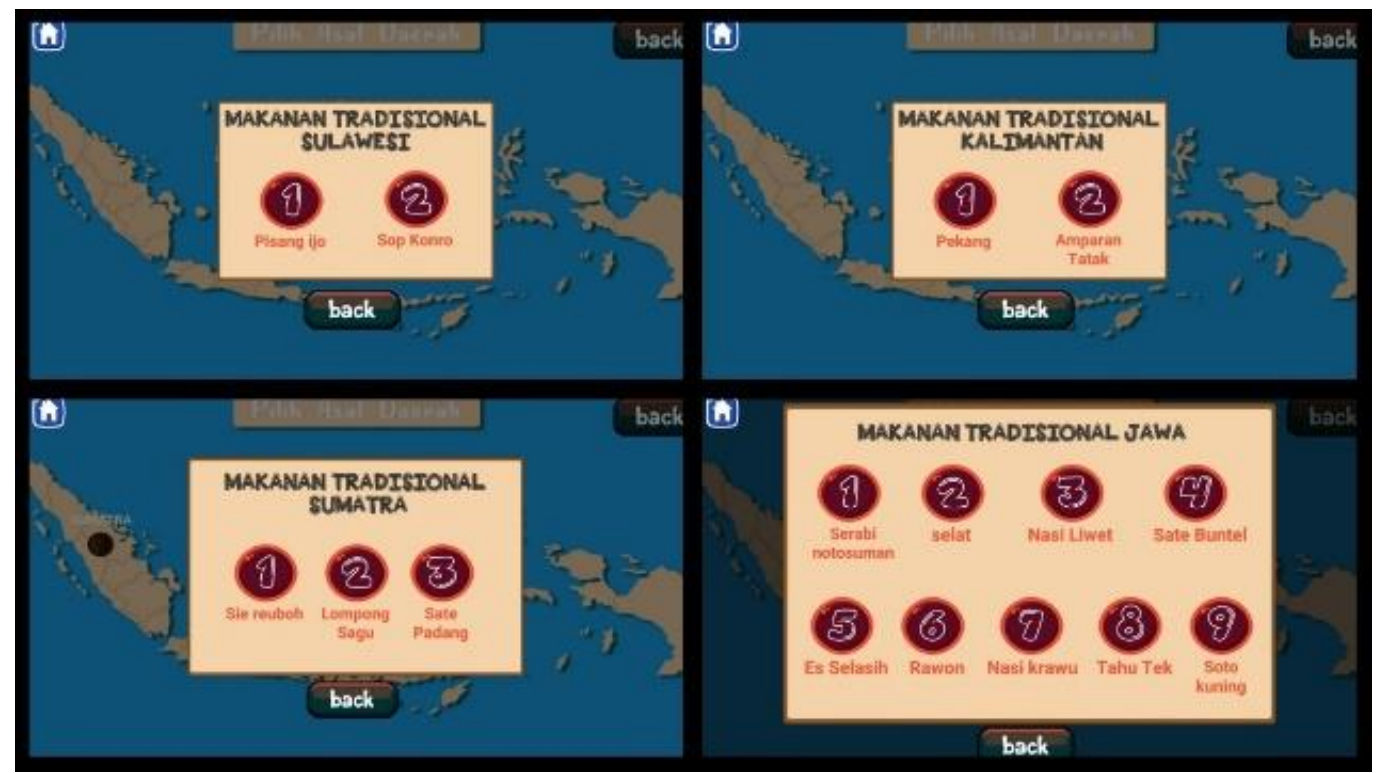

Gambar 6. Kumpulan Halaman Daftar Makanan

\subsection{Halaman Informasi Makanan}

Halaman informasi makanan berisi informasi singkat dari setiap makanan, diperlihatkan pada Gambar 7. Terdapat 5 tombol dalam kotak dialog, setiap tombol berisi informasi yang berbeda meliputi asal usul penamaan, lokasi, cara memasak, cita rasa, komposisi bahan, dan kapan makanan tradisional dimasak.

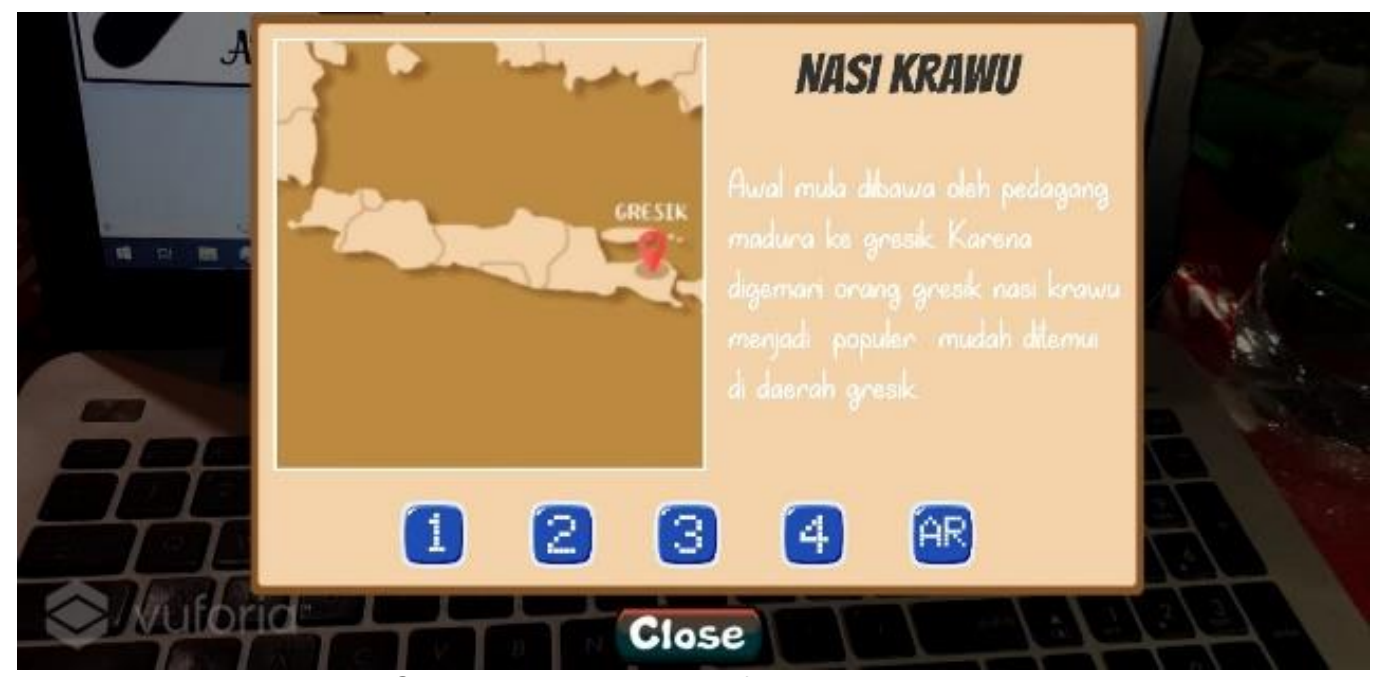

Gambar 7. Halaman Informasi Makanan

\subsection{Halaman AR}

Halaman AR memiliki fungsi menampilkan objek 3D makanan tradisional, untuk memunculkan objek 3D pengguna diharuskan memindai marker terlebih dahulu. Objek 3D akan tampil diatas marker secara realtime, terdapat tombol opsi yang bergambar 9 titik untuk menampilkan kembali informasi makanan. Simulasi menampilkan objek 3D dapat dilihat pada Gambar 8. 


\begin{tabular}{ll} 
Jurnal informatika & e-ISSN : $2686-1917$ \\
sthe & p-ISSN : $2657-0653$ \\
\hline
\end{tabular}

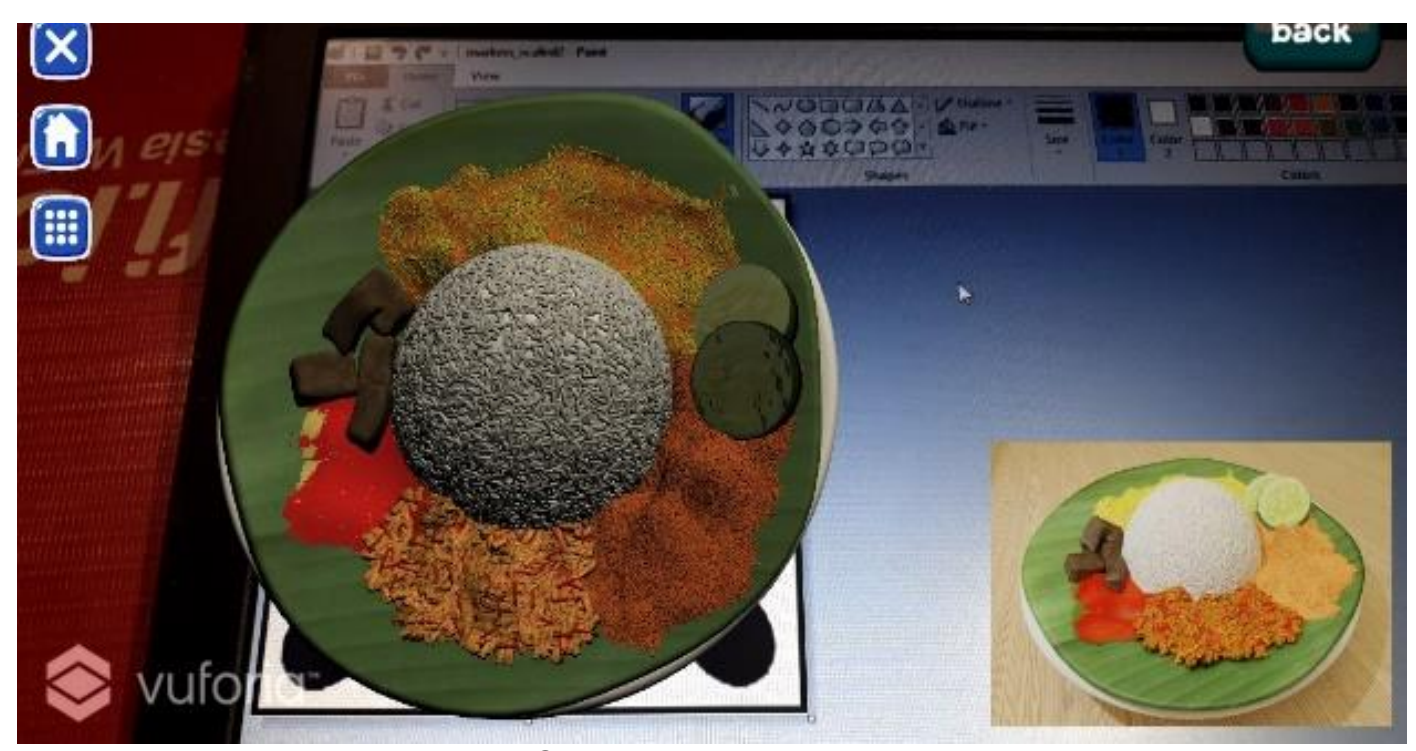

Gambar 8. Halaman AR

\subsection{Pengujian Black Box}

Black box testing adalah pengujian terhadap tampilan, pengguna, dan fungsi sistem [9]. Pengujian ini memastikan bahwa tampilan sudah sesuai dengan rancangan dan fungsi input output sistem berjalan sesuai yang diharapkan. Pengujian sistem menggunakan smartphone Samsung galaxy note 9 . Sistem berjalan dengan baik, tidak ada kesalahan fungsi maupun UI.

\subsection{Pengujian System Usability Scale (SUS)}

Pengujian usabilitas diperlukan untuk mengetahui kualitas pemakaian sistem yang memiliki 5 parameter ukur seperti seberapa mudah sistem dipelajari, seberapa efisiensi, mudah di ingat, apakah semua fungsi sesuai, dan seberapa menarik sistem yang dibuat [10].

SUS memiliki aturan pemakaian yaitu :

Skala tingkat responden sebesar 5 poin, skala ini menyatakan seberapa jauh pemahaman, ketertarikan, dan kemudahan yang dirasakan pengguna saat menggunakan aplikasi, berikut skala tingkat responden :
a. 1 sangat tidak setuju
b. 2 tidak setuju
c. 3 ragu
d. 4 setuju
e. 5 sangat setuju

Nilai yang didapat akan dihitung dalam perhitungan skor questioner, dengan ketentuan:

a. Pertanyaan bernomor ganjil nilainya dikurangkan dengan angka 1

b. Angka 5 dikurangkan dengan pertanyaan bernomor genap

c. Seluruh nilai dijumlahkan kemudian dikalikan dengan angka 2,5

d. Nilai seluruh responden dijumlah dan dibagi banyak responden

nilai rata - rata SUS menjadi acuan seberapa baik sistem diterima oleh pengguna, berikut skala interval nilai rata - rata SUS :
a. $0-20$ : Sangat buruk
b. $21-40$ : Buruk
c. $41-60$ : Cukup
d. $61-80$ : Baik
e. $81-100$ : Sangat baik

Berdasarkan tabel 2. Didapat nilai dari 30 responden yang menggunkan aplikasi dengan nilai rata - rata 78, Pada Gambar 9. pengguna memberikan penilaian 4 orang direntang, 41 60,14 orang direntang $61-80$, dan 12 orang pada $81-100$. Nilai 78 termasuk dalam rentang $61-$ 80 yang menandakan bahwa sistem telah diterima dengan baik oleh pengguna. 


.

Tabel 2. Hasil perhitungan System Usability Scale (SUS)

\begin{tabular}{cccccccccccc}
\hline P1 & P2 & P3 & P4 & P5 & P6 & P7 & P8 & P9 & P10 & Jumlah & Hasil \\
\hline 2 & 3 & 3 & 4 & 4 & 4 & 3 & 2 & 4 & 3 & 32 & 80 \\
3 & 3 & 3 & 4 & 4 & 4 & 3 & 4 & 3 & 3 & 34 & 85 \\
2 & 3 & 3 & 3 & 3 & 3 & 3 & 3 & 3 & 3 & 29 & 73 \\
4 & 3 & 3 & 1 & 4 & 1 & 4 & 1 & 4 & 1 & 26 & 65 \\
4 & 4 & 4 & 2 & 4 & 4 & 4 & 4 & 4 & 4 & 38 & 95 \\
4 & 4 & 4 & 4 & 4 & 3 & 3 & 4 & 4 & 4 & 38 & 95 \\
3 & 3 & 4 & 4 & 4 & 3 & 3 & 2 & 4 & 3 & 33 & 83 \\
3 & 4 & 4 & 4 & 4 & 3 & 2 & 3 & 2 & 3 & 32 & 80 \\
3 & 4 & 4 & 3 & 3 & 3 & 3 & 3 & 3 & 3 & 32 & 80 \\
3 & 3 & 3 & 3 & 3 & 2 & 3 & 2 & 3 & 2 & 27 & 68 \\
3 & 3 & 3 & 4 & 3 & 3 & 2 & 2 & 4 & 3 & 30 & 75 \\
3 & 3 & 4 & 4 & 4 & 0 & 4 & 3 & 4 & 3 & 32 & 80 \\
3 & 4 & 4 & 4 & 4 & 3 & 4 & 4 & 4 & 4 & 38 & 95 \\
2 & 2 & 3 & 3 & 2 & 1 & 1 & 2 & 3 & 2 & 21 & 53 \\
4 & 3 & 3 & 2 & 4 & 1 & 1 & 2 & 4 & 3 & 27 & 68 \\
3 & 4 & 4 & 4 & 4 & 4 & 4 & 4 & 4 & 4 & 39 & 98 \\
3 & 3 & 3 & 3 & 3 & 2 & 4 & 3 & 3 & 3 & 30 & 75 \\
3 & 4 & 3 & 4 & 3 & 3 & 4 & 4 & 0 & 4 & 32 & 80 \\
2 & 2 & 3 & 1 & 3 & 2 & 3 & 2 & 2 & 2 & 22 & 55 \\
2 & 3 & 3 & 4 & 4 & 3 & 4 & 3 & 4 & 4 & 34 & 85 \\
2 & 2 & 2 & 3 & 4 & 0 & 1 & 4 & 2 & 1 & 21 & 53 \\
4 & 3 & 4 & 3 & 3 & 2 & 4 & 3 & 3 & 4 & 33 & 83 \\
4 & 2 & 4 & 2 & 4 & 1 & 4 & 3 & 4 & 2 & 30 & 75 \\
4 & 4 & 4 & 4 & 4 & 4 & 4 & 4 & 4 & 4 & 40 & 100 \\
3 & 3 & 3 & 3 & 4 & 3 & 4 & 3 & 4 & 4 & 34 & 85 \\
3 & 3 & 4 & 2 & 4 & 1 & 3 & 3 & 3 & 4 & 30 & 75 \\
3 & 3 & 4 & 3 & 3 & 2 & 3 & 2 & 3 & 3 & 29 & 73 \\
2 & 3 & 3 & 4 & 2 & 4 & 3 & 3 & 3 & 3 & 30 & 75 \\
3 & 3 & 2 & 4 & 3 & 1 & 3 & 4 & 2 & 3 & 28 & 70 \\
2 & 4 & 3 & 4 & 3 & 2 & 4 & 4 & 3 & 4 & 33 & 83 \\
& & & & & Nilai rata-rata & & & & & 78 \\
\hline
\end{tabular}

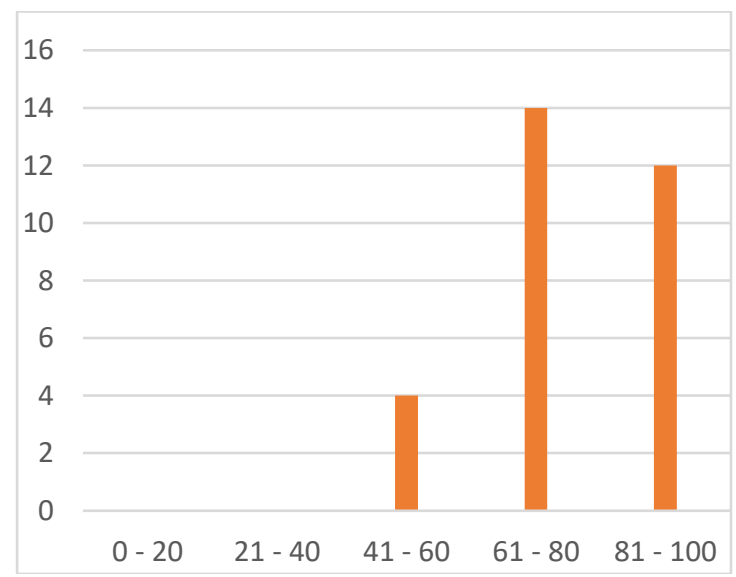

Gambar 9. Grafik perhitungan SUS 


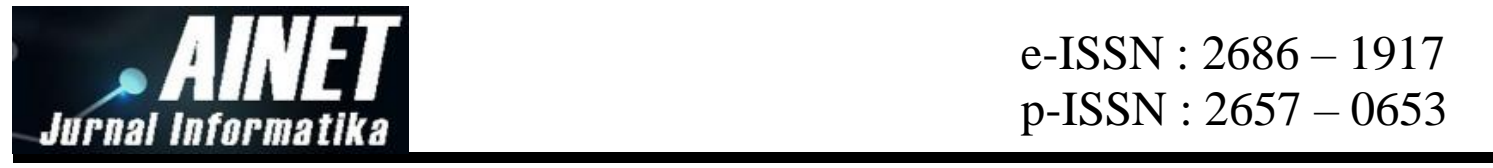

\section{Kesimpulan}

Sistem AR Makanan tradisional telah selesai dibangun, sistem mampu memperkenalkan makanan tradisional kepada masyarakat umum dengan cara yang unik dan menarik. Sistem berjalan sesuai yang diharapkan dan tanpa gangguan berdasarkan hasil pengujian black box. Respon positif juga diberikan oleh responden, dibuktikan nilai rata-rata SUS mencapai 78 yang berarti sistem diterima dengan baik. Harapan kami dengan sistem ini dapat membuat makanan tradisional dikenal oleh banyak orang. Sistem ini juga memiliki batasan seperti belum dapat digunakan di berbagai sistem operasi, sistem hanya dapat dijalankan di sistem operasi android. Sistem hanya mampu menampilkan 16 asset makanan tradisional, diharapkan penelitian selanjutnya sistem yang dikembangkan mampu menampilkan asset makanan yang lebih banyak serta menampilkan objek 3D makanan tradisional yang semakin realistis, dan interaktif.

\section{Referensi}

[1] A. S. P. Tyas, "Identifikasi kuliner lokal Indonesia dalam pembelajaran bahasa Inggris," J. Pariwisata Terap., vol. 1, no. 1, pp. 38-51, 2017.

[2] A. Sanna and F. Manuri, "A survey on applications of augmented reality," Adv. Comput. Sci. an Int. J., vol. 5, no. 1, pp. 18-27, 2016.

[3] J. G. S. Aguilar and I. A. Aguilar, "Interactions between human, computer and food," Food Nutr OA, vol. 2, no. 2, p. 116, 2019.

[4] A. Prasetio, N. NURHADI, and M. MULYADI, "Perancangan Aplikasi Augmented Reality Pengenalan Tata Surya Berbasis Android Pada SD Negeri 139/IV Kota Jambi," J. Process., vol. 14, no. 2, pp. 94-104, 2019.

[5] D. E. Kurniawan, A. Dzikri, M. Suriya, Y. Rokhayati, and A. Najmurrokhman, "Object Visualization Using Maps Marker Based On Augmented Reality," in 2018 International Conference on Applied Engineering (ICAE), 2018, pp. 1-5.

[6] M. E. Apriyani and R. Gustianto, "Augmented Reality sebagai Alat Pengenalan Hewan Purbakala dengan Animasi 3D menggunakan Metode Single Marker," J. Infotel, vol. 2, no. 2, pp. 47-52, 2010.

[7] P. G. Crandall et al., "Development of an augmented reality game to teach abstract concepts in food chemistry," J. Food Sci. Educ., vol. 14, no. 1, pp. 18-23, 2015.

[8] S. S. Saputri and E. Sudarmilah, "Game Edukasi Mitigasi Bencana Banjir "Tirta Si Pejuang Banjir," JoTI, vol. 1, no. 1, pp. 10-19, 2019.

[9] B. H. Purnomo, "AR Edugame Ayo Cintai Lingkungan Sebagai Media Pembelajaran Siswa Sekolah Dasar," Khazanah Inform. J. IImu Komput. dan Inform., vol. 1, no. 1, pp. 35-39, 2015.

[10] Z. Sharfina and H. B. Santoso, "An Indonesian adaptation of the system usability scale (SUS)," in 2016 International Conference on Advanced Computer Science and Information Systems (ICACSIS), 2016, pp. 145-148. 